\title{
Monitoring treatment response in metastasic colorectal cancer: Economic evaluation of PrediCTC versus computed tomography scan
}

Global \& Regional Health Technology Assessment

Volume 2019: 1-10

(C) The Author(s) 2019

Article reuse guidelines: sagepub.com/journals-permissions DOI: $|0.1| 77 / 22842403$ | 985833 | journals.sagepub.com/home/grh @SAGE

\author{
Cristina Antón Rodríguez1 (D), Miguel Abal Posada², \\ Lorena Alonso Alconada ${ }^{2}$, Sonia Candamio Folgar', \\ Rafael López López ${ }^{2}$ and Carlos Martín-Saborido'
}

\begin{abstract}
Background: Late state colorectal cancer treatments have important side effects that should be avoided in patients where drug effectiveness is not adequate. PrediCTC is a new biomarkers blood test developed to determinate the chemotherapy response in unresectable metastatic colorectal cancer patients that could allow to obviate unnecessary treatments. Aim: To assess from the Spanish Societal Perspective the cost-utility of the test PrediCTC compared to the computed tomography in aim to evaluate chemotherapy treatment response in late stage colorectal cancer patients. Methods: Based on the results of Barbazán et al., a Markov model has been developed, in which the different lines and cycles that the colorectal patient can receive and how they can move between them according to the computed tomography or PrediCTC have been represented. The effectiveness has been expressed in quality adjusted life years (QALYs), avoiding adverse events. Results: Base case analysis shows savings in different types of costs for PrediCTC (per patient): $€ I 4.30$ in those arise from adverse events, $€ 22,345.73$ in chemotherapy costs, $€ 4849.6 \mathrm{I}$ in other direct costs, and $€ 306.2 \mathrm{I}$ in indirect costs. Although computed tomography I2-week assessed patients gain 0.17QALYs compared with PrediCTC. Conclusions: From the Spanish Societal Perspective, PrediCTC is not a cost-utility option but allows to identify earlier patients who are not benefiting from first-line chemotherapy avoiding unnecessary side effects and costs.
\end{abstract}

\section{Keywords}

Cost-effectiveness, biomarkers, tumor, colorectal cancer, adverse events, monitoring

Date received: 10 September 2018; accepted: 15 April 2019

\section{Introduction}

Colorectal cancer is the fourth cause of cancer-related death and the metastasis appearance leads to a significant survival rate reduction. ${ }^{1}$ When the disease is unresectable, the therapeutic options are limited to systemic treatments with chemotherapy which are not always well tolerated by the patients. Being able to perform a suitable monitoring treatment response in these patients allows us to avoid administering treatments with notable side effects which are not producing any benefits to the patient. ${ }^{2}$

The tumor burden, metastases location, and treatment response are currently assessed with computed tomography
(CT) scans according to the RECIST criteria (Response Evaluation Criteria in Solid Tumors). Ramón Domínguez

\footnotetext{
'Health Technology Assessment Unit, Faculty of Health Science, Universidad Francisco de Vitoria, Madrid, Spain

${ }^{2}$ Translational Medical Oncology Group (Oncomet), CIBERONC, Health Research Institute of Santiago (IDIS), University Hospital of Santiago de Compostela (SERGAS), Santiago de Compostela, Spain

Corresponding author:

Cristina Antón Rodríguez, Health Technology Assessment Unit, Faculty of Health Science, Universidad Francisco de Vitoria, Ctra de Pozuelo Majadahonda, Km I,800, 28223 Pozuelo de Alarcón, Madrid, Spain. Email: c.anton@ufv.es
} 


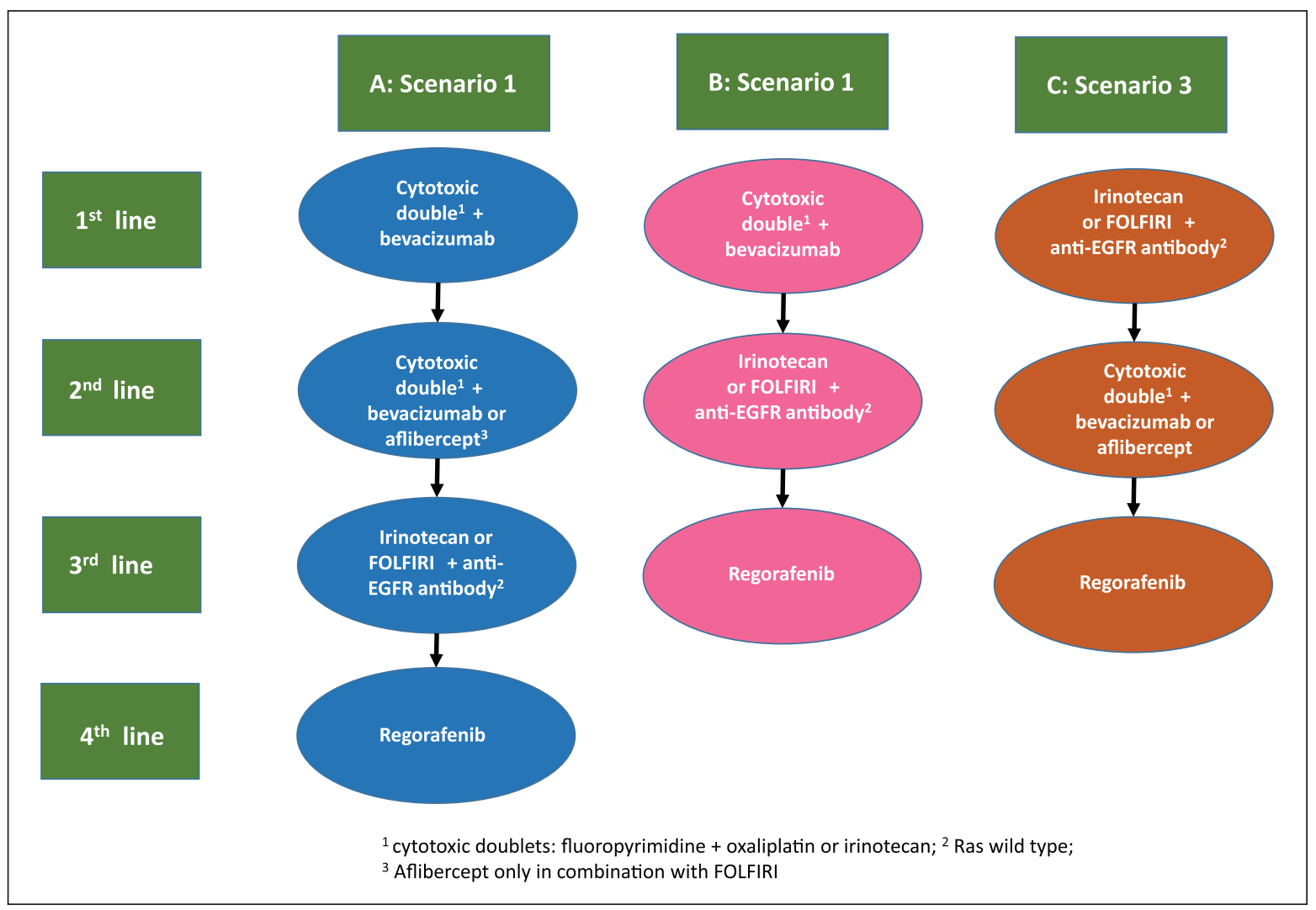

Figure I. Strategic scenarios in the continuum of care of metastatic colorectal cancer from " 2014 Metastatic colorectal cancer: ESMO Clinical Practice Guidelines for diagnosis, treatment and follow up."5

Foundation has developed a specific epithelial and mesenchymal tissue marker panel from peripheral blood (GAPDH, VIL1, CLU, TIMP1, LOXL, ZEB2), to be able to predict with greater accuracy the first-line chemotherapy treatment response in patients with metastatic colorectal (PrediCTC). ${ }^{2}$

Tumor cells detection in blood (CTC) via the Cell Search ${ }^{\mathrm{TM}}$ System has already been assessed by the Agency for the Evaluation of Health Technologies of Andalusia (AETSA) in its emerging technologies observatory as metastatic breast cancer patients monitoring tool, but the comparative costeffectiveness analysis with the current clinical practice was not included in the report and other specific colorectal cancer liquid biopsy treatment monitoring tool has not been evaluated in Spain. ${ }^{3}$ The main objective of our study is to carry out a cost-utility assessment of PrediCTC compared to CT monitoring the first-line chemotherapy response in patients with unresectable metastatic colorectal cancer from the Spanish Societal Perspective.

\section{Methods}

\section{Study design}

The model developed for this economic assessment takes as a reference the one published by the National Institute for
Health and Care Excellence (NICE) created to evaluate the KRAS gene mutation detection test and the 2014 Metastatic colorectal cancer: ESMO (European Society for Medical Oncology) Clinical Practice Guidelines for the diagnosis, treatment, and follow-up (Figures 1 and 2).,5

With a lifetime horizon (5 years were modeled using 240 cycles) based on the clinical trials survival data and the Barbazán et al. ${ }^{2}$ (Tables 1 and 2) and the expert panel consensus. ${ }^{2}$ Figure 2 represents the model developed for this study where we have represented the four treatment lines available for these patients. Each treatment line has eight possible health states called "cycles," each cycle lasting 4 weeks. After cycle 3 and cycle 6 in all the treatment lines, the patients chemotherapy response will be assessed by a CT, except in the first-line treatment in which the patient after cycle 3 has two options: be evaluated through CT or PrediCTC. Also, the first line differs from the other treatment lines because we have the "Break" state, lasting 4 weeks, where patients are in remission without treatment and after which they will continue in the same line. Finally, we have the absorbing state of "Death" where patients cannot move for any other state.

Arrows represents possible transition at the end of every 4 weeks during the OS since the diagnostic. For example, first-line treatment possible transitions: 


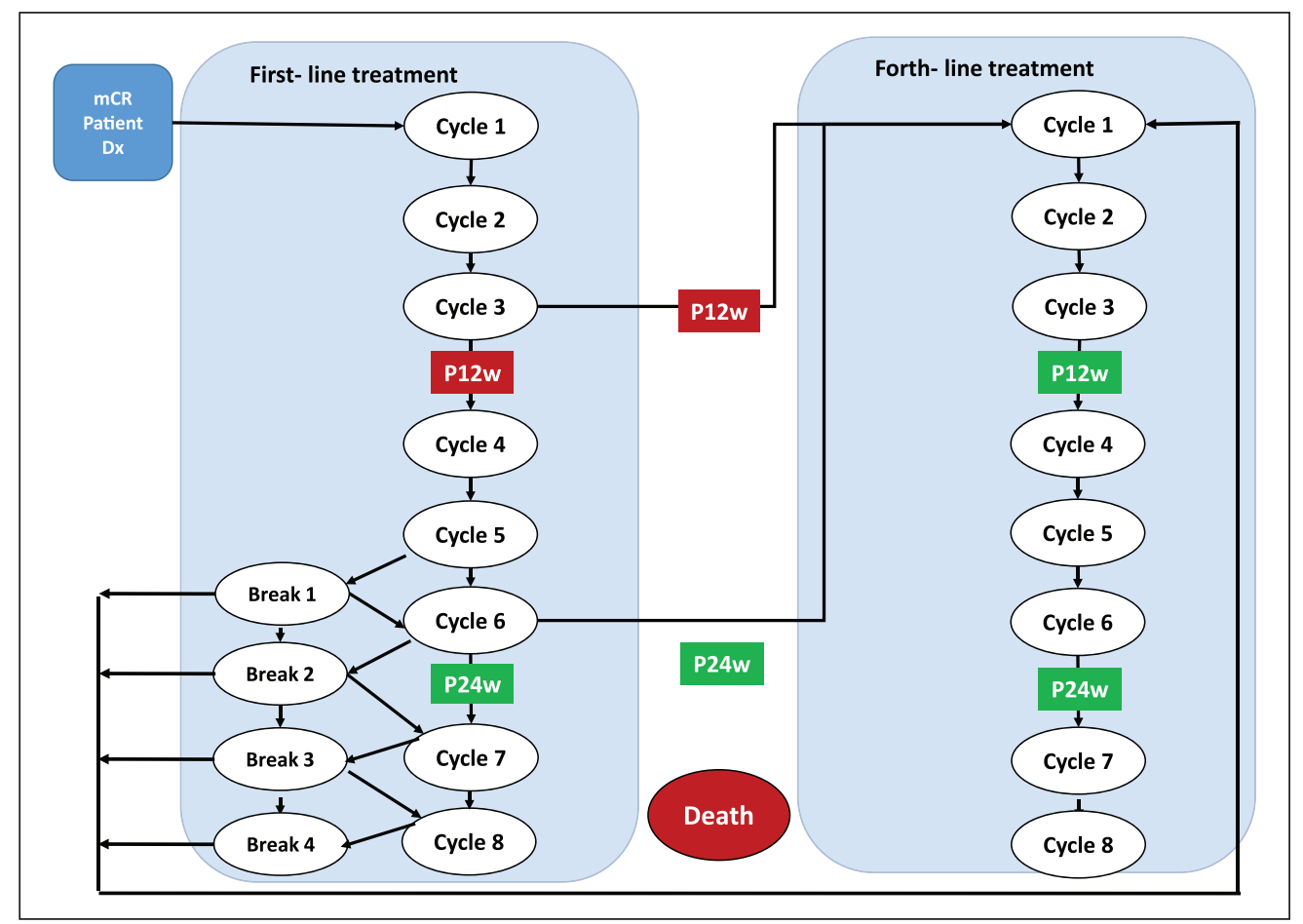

Figure 2. Markov model diagram where CT is used as cancer monitoring chemotherapy response tool every I 2 weeks (three cycles) in all the treatment lines and through PrediCTC or CT after the first three chemotherapy cycles in the first treatment line.

Table I. Comparison of therapy response-based patient classification between PrediCTC and first computed tomography evaluation.

Patient classification based on CT and PrediCTC markers

\begin{tabular}{llcc}
\hline CT & PrediCTC & $N(\%)$ & Mean OS (95\% Cl) months \\
\hline Responder & Responder & $33(67 \%)$ & $24.4(20.8-28.1)$ \\
Responder & Non-responder & $13(27 \%)$ & $14.4(8.9-20.0)$ \\
Non-responder & Non-responder & $3(6 \%)$ & $5.1(1.4-8.8)$ \\
\hline
\end{tabular}

Adapted from Barbazán et al. ${ }^{2}$

CT: computed tomography; OS: overall survival; $\mathrm{Cl}$ : confidence interval.

Table 2. Therapeutic regimens and OS (overall survival) and PFS (progression-free survival) Kaplan-Meyer curves digitized references.

\begin{tabular}{|c|c|c|}
\hline Therapeutic schedule & PFS & OS \\
\hline FOLFOX & Bokemeyer et al. ${ }^{6}$ & Bokemeyer et al. ${ }^{7}$ \\
\hline FOLFOX-cetuximab & Bokemeyer et al. ${ }^{6}$ & Bokemeyer et al. $^{7}$ \\
\hline FOLFOX-bevacizumab & Hecht et al. ${ }^{8}$ and Giantonio et al. ${ }^{9}$ & Hecht et al. ${ }^{8}$ and Giantonio et al. ${ }^{9}$ \\
\hline FOLFOX-panitumumab & Douillard et al. ${ }^{10}$ & Douillard et al. ${ }^{10}$ \\
\hline FOLFIRI & Peeters et al. ${ }^{\prime \prime}$ & Peeters et al. ${ }^{\prime \prime}$ \\
\hline FOLFIRI-bevacizumab & Loupakis et al. ${ }^{12}$ & Loupakis et al. ${ }^{12}$ \\
\hline FOLFIRI-cetuximab & Heinemman et al. ${ }^{13}$ & Heinemman et al. ${ }^{13}$ \\
\hline FOLFIRI-aflibercept & Van Cutsem et al. ${ }^{14}$ & Van Cutsem et al. ${ }^{14}$ \\
\hline 5FU-bevacizumab & Kabbinavar et al. ${ }^{15}$ & Kabbinavar et al. ${ }^{15}$ \\
\hline 5-Fluorouracil (5FU) & Kabbinavar et al. ${ }^{15}$ & Kabbinavar et al. ${ }^{15}$ \\
\hline Capecitabine & Cunningham et al. ${ }^{16}$ & Cunningham et al. ${ }^{16}$ \\
\hline Regorafenib & Grothey et al. ${ }^{17}$ & Grothey et al. ${ }^{17}$ \\
\hline BST & Van Cutsem et al. ${ }^{18}$ & Van Cutsem et al. ${ }^{18}$ \\
\hline
\end{tabular}

BST: best support treatment. 
Table 3. Therapeutic schedules and percentage of patients treated in each line.

\begin{tabular}{|c|c|c|c|c|}
\hline Therapeutic Schedule & First line & Second line & Third line & Fourth line \\
\hline FOLFOX & $15.00 \%$ & $4.93 \%$ & & \\
\hline FOLFOX-cetuximab & $11.43 \%$ & $3.43 \%$ & & \\
\hline FOLFOX-bevacizumab & $29.98 \%$ & & $2.50 \%$ & $1.25 \%$ \\
\hline FOLFOX-panitumumab & $22.87 \%$ & $3.43 \%$ & & \\
\hline FOLFIRI & $5.00 \%$ & $8.92 \%$ & & \\
\hline FOLFIRI-bevacizumab & $2.14 \%$ & $35.68 \%$ & & \\
\hline FOLFIRI-cetuximab & $8.58 \%$ & & & \\
\hline FOLFIRI-aflibercept & & $14.87 \%$ & & \\
\hline 5FU-bevacizumab & $5.00 \%$ & $3.75 \%$ & & \\
\hline 5-Fluorouracil (5FU) & & & $23.50 \%$ & II.75\% \\
\hline Capecitabine & & & $16.50 \%$ & $8.25 \%$ \\
\hline Regorafenib & & & $7.50 \%$ & $3.75 \%$ \\
\hline BST & & $25 \%$ & $50 \%$ & $75 \%$ \\
\hline
\end{tabular}

BST: best support treatment.

Patients after Cycle 1 can move to Cycle 2 same line or Death state.

After Cycle 2 patients can move to Cycle 3 same line or Death state.

After Cycle 3 patient's treatment response will be evaluated through CT or PrediCTC moving to Cycle 4 same line if he is a responder, Cycle 1 second treatment line if he is a non-responder or to Death state.

After Cycle 4 patients can move to Cycle 5 same line or Death state.

After Cycle 5 patients can move to Cycle 6, Break 1 or Death state.

After Cycle 6 patients treatment response will be assessed through CT moving to Cycle 7 or Break 2 if he is responding, to Cycle 1 next line if he is not responding or to the Death state.

After Cycle 7 patients can move to Break 3, Cycle 8 or Death state.

After Cycle 8 patients can move to Break 4, next line Cycle 1 or Death state.

\section{Alternatives to compare and efficacy estimation}

The alternatives to be compared are as follows:

1. Treatment assessment response monitored with CT every 12 weeks.

2. Treatment assessment response monitored with PrediCTC after "Cycle 3" first-line treatment and from that with CT scan every 12 weeks.

Computed tomography transition probabilities used are those drawn from the main clinical trials of the different treatments assigned to the patients. These four lines chemotherapy transition probabilities were obtained with the Plot Digitizer program, digitizing progression-free survival (PFS) and overall survival (OS) Kaplan-Meyer curves of the randomized clinical trial published. All the figures digitized to obtain the data were adjusted with a minimum $R^{2}$ of $98 \%$ and some of them were divided into two to better adjust the final periods. Therapeutic schedules and distribution of the patients were defined by the adjustment of the 2014 ESMO Metastatic Colorectal Cancer Guidelines to the daily practice of the Compostela University Hospital Oncology Service.

The PrediCTC test transition probabilities were drawn from the study carried out at the Translational Medical Oncology Unit from the Health Research Institute, ${ }^{2}$ Table 1 , which indicates that in week 16 , out of $100 \%$ of the patients classified as treatment responders using $\mathrm{CT}$, $71.7 \%$ (33 from 46) were classified as responders and $28.3 \%$ (13 from 26) as non-responders when using the PrediCTC; and $100 \%$ patients classified in progression with CT were non-responders with PrediCTC. Under the expert panel consensus, the application week of the transition mediated by the PrediCTC test was change from week 16 to week 12 .

The treatment schedules and the references used to obtain the OS, PFS, percentage of drop-outs due to adverse effects, and the grade 3 and 4 side effects (neutropenia, febrile neutropenia, and neurotoxicity, diarrhea and handfoot syndrome) are shown in Table 2, percentage of patients receiving each treatment defined by the experts in Table 3, and transition probabilities in Table 4 .

To reduce the treatment toxicities, some patients with stable illness, partial or complete response can take a "chemo break" or programmed rest in the treatment and then return once again to the same therapy schedule. The "break" average duration in the first-line treatment 
Table 4. Model transition probabilities between cycles and treatment lines calculated through the OS and PFS in the studies referred in Table 2.

\begin{tabular}{|c|c|c|c|c|}
\hline Transition probabilities & First line & Second line & Third line & Fourth line \\
\hline Cycle I to Cycle 2 & 0.9602 & 0.8547 & 0.7615 & 0.6888 \\
\hline Cycle 2 to Cycle 3 & 0.9119 & 0.6574 & 0.3883 & 0.2223 \\
\hline Cycle 3 to Cycle 4 & 0.8343 & 0.5354 & 0.2292 & 0.0579 \\
\hline Cycle 4 to Cycle 5 & 0.7549 & 0.4248 & 0.1001 & 0.0000 \\
\hline Cycle 5 to Cycle 6 & 0.6729 & 0.3236 & 0.1001 & 0.0000 \\
\hline Cycle 6 to Cycle 7 & 0.5883 & 0.2305 & 0.1001 & 0.0000 \\
\hline Cycle 7 to Cycle 8 & 0.5025 & 0.1440 & 0.1001 & 0.0000 \\
\hline Cycle 5/6/7/8 to "Break" & 0.0375 & 0.0000 & 0.0000 & 0.0000 \\
\hline Progression after Cycle I & 0.0267 & 0.1065 & 0.1789 & 0.2395 \\
\hline Progression after Cycle 2 & 0.0583 & 0.2644 & 0.4869 & 0.6290 \\
\hline Progression after Cycle 3 & 0.1126 & 0.3432 & 0.5821 & 0.7196 \\
\hline Progression after Cycle 4 & 0.1690 & $0.4|2|$ & 0.6494 & 0.7809 \\
\hline Progression after Cycle 5 & 0.2283 & 0.4731 & 0.7009 & 0.8222 \\
\hline Progression after Cycle 6 & 0.2904 & 0.5276 & 0.7484 & 0.8527 \\
\hline Progression after Cycle 7 & 0.3538 & 0.5769 & 0.8034 & 0.8815 \\
\hline Progression after Cycle 8 & 0.4164 & 0.6224 & $0.84 \mid 4$ & 0.9005 \\
\hline Death after Cycle I & 0.0131 & 0.0388 & 0.0596 & 0.0717 \\
\hline Death after Cycle 2 & 0.0297 & 0.0782 & 0.1248 & 0.1487 \\
\hline Death after Cycle 3 & 0.0531 & 0.1214 & 0.1887 & 0.2225 \\
\hline Death after Cycle 4 & 0.0761 & 0.1631 & 0.2506 & 0.2191 \\
\hline Death after Cycle 5 & 0.0613 & 0.2033 & 0.1991 & 0.1778 \\
\hline Death after Cycle 6 & 0.0838 & 0.2420 & 0.1516 & 0.1473 \\
\hline Death after Cycle 7 & 0.1062 & 0.1927 & 0.0965 & 0.1185 \\
\hline Death after Cycle 8 & 0.5461 & 0.3776 & 0.1586 & 0.0995 \\
\hline
\end{tabular}

OS: overall survival; PFS: progression-free survival.

described in the OPTIMOX 2 study is 3.9 months. ${ }^{19}$ We have include four cycles average of "Break" through which a $15 \%$ of first-line patients will transit assuming that these breaks starts from cycle 4 up to cycle 8 continuously until the percentage per line explained above has been reached.

When the chemotherapy outweigh the possible benefits, the patient only receives best supportive care (BSC). The percentage of patients with BSC is of $25 \%$ after first-line treatment, $50 \%$ after second-line treatment, and $75 \%$ after the third line of chemotherapy (Table 3 ).

The utilities of each chemotherapy schedule and their side effects included in the model are summarized in Table 5; population evaluated in these studies belongs to different countries like USA, UK, and Australia. General mortality data have not been included because OS does not allow to differentiate the mortality due to colorectal cancer from others.

\section{Cost estimation}

The resources, unit cost, and units consumed identification to calculate the healthcare and non-healthcare direct cost and the indirect costs derive from the bibliographical references and the data provided by the panel of experts (Tables 6 to 9). All the costs have been updated to $€ 2015$
Table 5. Treatments and their side effects utilities.

\begin{tabular}{lll}
\hline Treatment & Utility & Reference \\
\hline FOLFOX & 0.780 & Lairson et al. ${ }^{20}$ \\
FOLFIRI & 0.750 & Starling et al. ${ }^{21}$ \\
5-Fluorouracil & 0.780 & Orchard et al. ${ }^{22}$ \\
Capecitabine & 0.780 & Orchard et al. ${ }^{22}$ \\
BST & 0.690 & Hoyle et al. ${ }^{23}$ \\
Regorafenib & 0.730 & Grothey et al. ${ }^{17}$ \\
Cetuximab & 0.745 & Hoyle et al..$^{23}$ \\
Panitumumab & 0.810 & Hoyle et al. ${ }^{23}$ \\
Bevacizumab & 0.800 & Orchard et al. ${ }^{22}$ \\
Aflibercept & 0.800 & Orchard et al. ${ }^{22}$ \\
\hline Side effect & Utility & Reference \\
\hline Febrile neutropenia & 0.660 & Orchard et al. ${ }^{22}$ \\
Peripheral neuropathy & 0.440 & Currie et al. ${ }^{24}$ \\
Diarrhea & 0.610 & Zeng et al. ${ }^{25}$ \\
Palmoplantar erythrodysesthesia & 0.620 & Zeng et al. ${ }^{25}$ \\
\hline
\end{tabular}

BST: best support treatment.

with the correspondent Consumer Price Index correction factor.

Included within the direct healthcare costs are different chemotherapy costs of the cycles and what 
Table 6. Chemotherapy schedules and best support treatment for each treatment line cycle (4 weeks).

\begin{tabular}{|c|c|}
\hline Therapeutic schedule & $\begin{array}{l}\text { Cost calculated per } \\
\text { treatment line cycle }\end{array}$ \\
\hline $\begin{array}{l}\text { FOLFOX: oxaliplatin ( } 85 \mathrm{mg} / \mathrm{m}^{2} \text { iv every } 2 \text { weeks); folinic acid }\left(100 \mathrm{mg} / \mathrm{m}^{2} / \text { day iv); } 5 \text {-fluorouracil }\right. \\
\left(400 \mathrm{mg} / \mathrm{m}^{2} / \text { day iv bolus and } 1200 \mathrm{mg} / \mathrm{m}^{2} / \text { day continuous infusion) }\right.\end{array}$ & $€ 3344.74$ \\
\hline $\begin{array}{l}\left.\text { FOLFIRI: irinotecan ( } 180 \mathrm{mg} / \mathrm{m}^{2} \text { iv bolus }\right) \text {; folinic acid }\left(100 \mathrm{mg} / \mathrm{m}^{2} / \text { day iv }\right) ; 5 \text {-fluorouracil }\left(400 \mathrm{mg} / \mathrm{m}^{2} / \text { day }\right. \\
\text { iv bolus, and } 1200 \mathrm{mg} / \mathrm{m}^{2} / \text { day continuous infusion) }\end{array}$ & $€ 3043.75$ \\
\hline 5-Fluorouracil-folinic acid: folinic acid $\left(500 \mathrm{mg} / \mathrm{m}^{2} \mathrm{iv}\right) ; 5$-fluorouracil $\left(500 \mathrm{mg} / \mathrm{m}^{2} \mathrm{iv}\right), 6$ weeks every 8 & $€ 1441.19$ \\
\hline CAPECITABINE: capecitabine ( $1250 \mathrm{mg} / \mathrm{m}^{2} / 12$ hours, during 14 days, followed by 7 -day resting period) & $€ 501.1 \mathrm{I}$ \\
\hline $\begin{array}{l}\text { Regorafenib: regorafenib }(160 \mathrm{mg} / 24 \text { hours oral, } 20 \% \text { patients with adjusted dose }(80 \mathrm{mg} / 24 \text { hours }) \text { due } \\
\text { to toxicity, } 3 \text { weeks of treatment followed by I-week resting period) }\end{array}$ & $€ 2818.97$ \\
\hline Aflibercept: aflibercept ( $4 \mathrm{mg} / \mathrm{kg}$ each 2 weeks) & $€ 2446.51$ \\
\hline Cetuximab: cetuximab $\left(400 \mathrm{mg} / \mathrm{m}^{2}\right.$ initial dose and $250 \mathrm{mg} / \mathrm{m}^{2}$ maintenance dose) & $€ 3942.66$ \\
\hline Panitumumab: panitumumab (6 mg/kg, once every 2 weeks) & $€ 3626.59$ \\
\hline Bevacizumab: bevacizumab ( $7.5 \mathrm{mg} / \mathrm{kg}$ weighted, every 2 weeks $)$ & $€ 3994.14$ \\
\hline Best support treatment (BST), Pericay et al. ${ }^{26}$ & $€ 253.86$ \\
\hline
\end{tabular}

iv: intravenous.

Table 7. Adverse events grade 3 and 4 treatment cost per cycle (4 weeks).

\begin{tabular}{|c|c|}
\hline Grade 3 and 4 adverse reaction & Treatment cost per cycle (4 weeks) \\
\hline Neutropeniaa Pericay et al. ${ }^{26}$ & $€ 98.77$ \\
\hline Febrile neutropenia ${ }^{a}$ Pericay et al. ${ }^{26}$ & $€ 4687.93$ \\
\hline Neuropathy ${ }^{\text {P }}$ ericay et al. ${ }^{26}$ & $€ 0.5 \mathrm{I}$ \\
\hline Diarrhea $^{a}$ Pericay et al. ${ }^{26}$ & $€ 244.93$ \\
\hline $\begin{array}{l}\text { Hand-Foot syndrome Herrera et al. } .^{27} \text {; BOTPLUS } 2.0^{28} \text { (systemic dexamethasone } \\
8 \mathrm{mg} / / 2 \text { hours cycle days } \mathrm{I} \text { and } 5 \text { and piridoxine } 150-200 \mathrm{mg} / \text { day) }\end{array}$ & $€ 6.28$ \\
\hline
\end{tabular}

aDisaggregated cost not available. ${ }^{26}$

derives from its side effects, hospitalization costs, outpatient consultations, CT scan cost, PrediCTC test, and other complementary tests cost. For the calculation of the total cost of the different treatments, the dosage data from the technical reports of the medical products have been used, as well as the mean weight and body surface $\left(70.5 \mathrm{~kg}\right.$ and $\left.1.7 \mathrm{~m}^{2}\right)$, published by the National Institute of Statistics for individuals (men and women) over 65 years of age. In addition, the price published by the Official Body of Pharmacists has been used, applying a discount of $7.5 \%$ and of $4 \%$ to the orphan drugs established in articles 8, 9, and 10 of the Royal Decree Law 8/2010 modified by the Royal Decree Law 9/2011 and the costs of the intravenous infusion and day spent at hospital published by the Galician Health Service. $^{30}$ The cost of the BSC derives from the composition of the active ingredient, dosage, and distribution published in the study by Pericay et al. ${ }^{26}$ The pharmacological treatments included in the BSC are analgesics (delayed-release morphine, metamizole, fentanyl in patches and tablets, tramadol and midazolam), anti-cachetics (megestrol), antiemetics (oral ondansetron), and corticosteroids (dexamethasone and oral prednisone).
All adverse events cost included in the model are summarized in Table 7:

Neutropenia, febrile neutropenia, neuropathy, and diarrhea grade 3 and 4 cost per cycle were estimated from disaggregated resources consume by an expert panel from different Spanish hospitals (Parc Tauli Sanitary Corporation, Catalonia Oncology Institute and Santiago de Compostela Hospital Complex) but the label information is not available in the paper published.

As Hand-Foot syndrome cost is not detailed in Pericay et al., ${ }^{26}$ the cost estimation was calculated from the treatment explained in Herrera et al., ${ }^{27}$ study and the price published by the Official Body of Pharmacists using the same methodology describe above for the chemo treatment.

The direct healthcare costs not included in the chemotherapy treatment are follow-up treatment test (CT and PrediCTC) and those connected to hospital stays (hospitalization), consultations, emergencies and other direct costs which cover pharmaceutical treatments in 
Table 8. Other direct medical cost included.

\begin{tabular}{|c|c|}
\hline Other direct medical cost & Cost per cycle ( 4 weeks) \\
\hline Hospitalizations ${ }^{\text {a }}$ Corral et al. ${ }^{29}$ & $€|I| 5.62$ \\
\hline Medical consultations ${ }^{\text {a }}$ Corral et al. ${ }^{29}$ & $€ 757.69$ \\
\hline Other direct $\operatorname{cost}^{\mathrm{a}}$ (other drugs, pathological anatomy, and other exploratory test) Corral et al. ${ }^{29}$ & $€ 303.60$ \\
\hline CT SERGAS rates 30 & $€ 372.45$ (test cost) \\
\hline PrediCTC CHUS Experts panel; Public Prices Madrid Community ${ }^{31}$ & $€ \mid 10.60$ (test cost) \\
\hline
\end{tabular}

${ }^{a}$ Disaggregated cost not available. ${ }^{26}$

Table 9. Parameter distribution function included in the probabilistic sensitivity analysis.

\begin{tabular}{llc}
\hline Parameter & Form of data & Distribution \\
\hline Transition probabilities & Time to event & Lognormal \\
Costs & Resource counts (mean and SD) & Lognormal \\
Utility & Continuous non-zero (mean and SD) & Gamma \\
Disutility & Continuous non-zero (mean and SD) & Gamma \\
\hline
\end{tabular}

SD: standard deviation.

A discount rate of $3 \%$ has been applied to all costs and utilities. ${ }^{32}$

outpatient clinics, pathological anatomy, and other complementary test detailed in Table 8. PrediCTC resources consume (material and labor) and their cost was obtained from the Santiago de Compostela Hospital Complex. The sample management cost was based on 1 day ( 8 average hours) of work for each determination, the assumption that four samples could be evaluated at the same time and a laboratory technician $€ 1300$ cost per month. From the public rates for the Galician Health Service, the CT cost and the rest of non-chemotherapy sanitary direct cost from the phase IV colorectal cancer per patient during a 13 months (13.93 cycles) average follow-up taken from the Catalonia Colorectal Cancer Cost Study publish in 2015 (€15,539.05 hospitalizations; $€ 803.56$ others $€ 4,228,67) .{ }^{29}$

The direct costs not related to healthcare are those such as displacement costs and unofficial care, which are usually paid by the patient or their family. The hourly cost for unofficial care $(€ 8.25)$ has been calculated using data from the 4th Collective Agreement of the State Framework for services of people and the development of the promotion of personal autonomy, with a total of 40 hours per week. The cost of displacements is based on the cost of non-urgent healthcare transport (€38.52) published in the Official Bulletin of the Autonomous Community of Madrid, multiplied by an average of 2 , $1.5,1$, and 1 in first-, second-, third-, and fourth-line treatment, respectively. ${ }^{31}$

The indirect costs (productivity potential losses in productivity) have been estimated taking into account the average age of the patients and assuming that $90 \%$ are retired and the other $10 \%$ are permanently unable to work (assumption approved by the panel of experts). The average cost for permanent disability in Spain is $€ 906.66$ and $€ 995.59$ as average retirement cost. ${ }^{33,34}$
Base case analyses. The results of the model have been obtained analyzing the base case and classifying the costs by the following types: test costs, cost of adverse events, cost of chemotherapy, direct costs of the base case. The first-line results have been differentiated from the totals because in the rest of the treatment lines, the drivers of the model for the two alternatives are identical. The effectiveness is expressed in quality adjusted life years (QALYs), adverse effects and costs avoided.

Once the results of the base case were obtained, a univariate analysis was performed by varying the value of all parameters used in the model within a plausible range of $\pm 10 \%$ if we did not have the confidence interval or any other statistical dispersion. If CI was available, the upper and lower limits were used. In addition, we performed a probabilistic sensitivity analysis using random values taken from the probability distributions characterized by the average and standard deviation instead of using a fixed value for each parameter used in the base case. The distributions chosen were based on Briggs et al., handbook: "Decision modelling for health economic evaluation" and depicted in Table 9. ${ }^{35}$

\section{Results}

\section{Base case analysis}

Base case results show all cost typologies lower for the PrediCTC alternative (Table 10), mainly due to its higher sensitivity identifying patients who do not respond to first-line treatment, therefore avoiding treatment costs for patients who according to this test, will not respond to it.

The CT alternative achieves greater utility than PrediCTC despite the latter avoiding giving chemotherapy 
Table I0. Base case results (cost and utilities per patient).

\begin{tabular}{lllll}
\hline & PrediCTC & CT & Difference & \% Over \\
\hline Test cost & $€ 2727.12$ & $€ 2941.03 .39$ & $€-231.91$ & $7.84 \%$ \\
AE cost & $€ 93.36$ & $€ 107.66$ & $€-14.30$ & $15.32 \%$ \\
Chemotherapy cost & $€ 60,339.14$ & $€ 82,684.87$ & $€-22,345.73$ & $37.03 \%$ \\
Other medical cost & $€ 19,003.08$ & $€ 23,852.69$ & $€-4849.61$ & $25.52 \%$ \\
Total indirect cost & $€ 766.54$ & $€ 1072.75$ & $€-306.21$ & $39.95 \%$ \\
Total direct cost & $€ 82,162.70$ & $€ 109,586.25$ & $€-27,423.55$ & $33.38 \%$ \\
Total cost & $€ 83,252.87$ & $€ I 10,338.45$ & $€-27,085.57$ & $32.53 \%$ \\
Total QALYs & 0.67 & 0.83 & 0.17 & $-20.11 \%$ \\
\hline
\end{tabular}

AE: adverse events; CT: computed tomography; QALYs: quality adjusted life years.

Table I I. Probabilistic analysis results.

\begin{tabular}{|c|c|c|c|c|}
\hline & PrediCTC ${ }^{\circledR}$ & CT & Difference & $\%$ Over \\
\hline Test cost & $€ 2273.29$ & $€ 2946.43$ & $€-210.13$ & $7.68 \%$ \\
\hline$A E$ cost & $€ 92.74$ & $€ 107.54$ & $€-\mid 4.80$ & $15.86 \%$ \\
\hline Chemotherapy cost & $€ 60,146.48$ & $€ 82,562.01$ & $€-22,4 \mid 5.53$ & $37.27 \%$ \\
\hline Other medical cost & $€ 18,952.00$ & $€ 23,680.26$ & $€-4,728.26$ & $24.95 \%$ \\
\hline Total indirect cost & $€ 765.59$ & $€ 1079.24$ & $€-3 \mid 3.65$ & $40.97 \%$ \\
\hline Total direct cost & $€ 8 I, 927.5 \mathrm{I}$ & $€ 109,296.24$ & $€-27,368.72$ & $33.41 \%$ \\
\hline Total cost (IC 95\%) & $€ 83,0$ I5.4I (82,435.0I-83,595.8I) & $€ \mid 10,055.16(109, \mid 79.29-10,931.04)$ & $€-27,039.75$ & $32.57 \%$ \\
\hline Total QALY (IC 95\%) & $0.67(0.6621-0.6698)$ & $0.83(0.8265-0.8373)$ & 0.17 & $-19.95 \%$ \\
\hline
\end{tabular}

AE: adverse events; CT: computed tomography; QALYs: quality adjusted life years.

to more patients who will not respond to the treatment scheduled in the first line. This is due to the fact that the model is prepared to give patients less utility as they progress through the treatment lines and with PrediCTC, non-responder patients pass earlier to the second line of treatment. The average utility for the patient in first-, second-, third-, and fourth-line treatment for CT alternative is $0.54,0.20,0.06$, and 0.02, respectively, and for PrediCTC $0.37,0.17,0.05$, and 0.05 . For this reason, the incremental cost-effectiveness ratio (ICER) is not given as a result of the assessment due to the fact that the alternative is less effective in terms of usefulness (QALYs).

The percentage of patients who survives and moves to the next line treatment using PrediCTC to determinate the treatment response was $33 \%$ in the first line, 33\% in the second, $22 \%$ in the third, and $11 \%$ in the fourth. With the CT alternative, this percentage was $41 \%, 29 \%$, $20 \%$, and $10 \%$, respectively. With regard to adverse events, the PrediCTC alternative produces 0.12 adverse events less, with $€ 27,085$ saved per patient.

\section{Univariate sensitivity analysis and probabilistic results}

The univariate sensitivity analysis carried out does not show any significant change in the results. And the probabilistic sensitivity analysis provides similar results to the deterministic ones regarding the efficacy and all the cost areas analyzed (Table 11).
On a cost-efficacy level, represented by the 1000 repetitions performed for each alternative, PrediCTC remains the best option in $91.2 \%$ of the simulations (Figure 3 ).

\section{Discussion}

Although PrediCTC has shown a greater sensitivity to detect first-line early non-responder metastatic colorectal patients, compared to the computed tomography (CT) scans, National Oncology experts consider that Barbazán et al. ${ }^{2}$ is an exploratory study, with a small sample of 50 patients recruited by the University Hospital of Santiago de Compostela and does not allow to determinate which treatment should be given to the non-responder patients.

The main limits we faced were due to the fact that in the reference study, follow-up is only made on patients in the first line of treatment and no modifications are made to the patient approach given the test results. As a result, we cannot know the real response of the NR patients to the subsequent lines of treatment. Existing possibility is that this subgroup of patients with advanced colorectal cancer who are prematurely classified as NR may have some characteristic in common such as more aggressive tumors or special sensitivity to a particular type of treatment. This would substantially vary the results of effectiveness and usefulness in the subsequent lines and would make them differ from the assumptions made. However, for the moment, there are no data available 


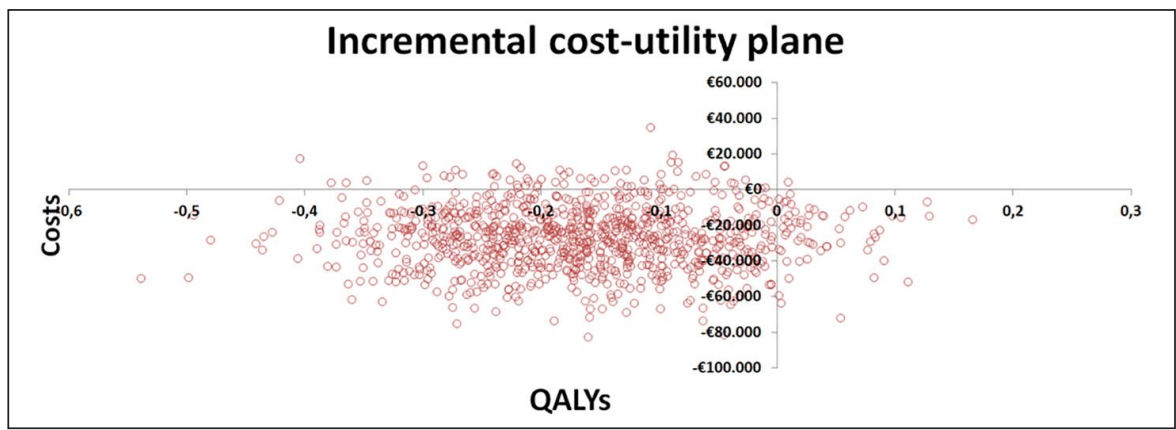

Figure 3. Incremental cost-effective plane.

which allows us to differentiate the results. Therefore, the transition probabilities and usefulness after the first line of treatment are the same for the other alternatives compared.

Most of the new clinical trials published after the selection done by the oncologist from the Santiago de Compostela University Hospital evaluate the efficacy or effectiveness of chemotherapy regimens that do not correspond to the ones used to treat the patients included in the Barbazan study and also most of them include biomarkers to select the treatment to be used.

A National Oncology expert's focus group was done to analyze the results of the cost-utility evaluation, their main conclusion was that PrediCTC should not replace CT but it could be added to the chemotherapy response assessment when other studies with a large sample prove its accuracy after the first cycle in the first treatment line and in the other clue moments were the treatment response has to be evaluated.

\section{Conclusion}

From the Spanish societal perspective, PrediCTC allows to identify patients that are not getting benefits from chemotherapy in unresectable metastatic colorectal cancers and therefore to avoid side effects and cost in nonresponder patients, but is not a cost-effectiveness option. Further studies are needed to investigate the real effectiveness of adapted second, third, and fourth chemo schedules for non-responder patients.

\section{Declaration of conflicting interests}

The author(s) declared no potential conflicts of interest with respect to the research, authorship, and/or publication of this article.

\section{Funding}

The author(s) received no financial support for the research, authorship, and/or publication of this article.

\section{ORCID iD}

Cristina Antón Rodríguez (iD https://orcid.org/0000-0001-8218 $-9780$

\section{References}

1. Jemal A, Bray F, Center MM, et al. Global cancer statistics. CA Cancer J Clin 2011; 61(2): 69-90.

2. Barbazán J, Muinelo-Romay L, Vieito $\mathrm{M}$, et al. A multimarker panel for circulating tumor cells detection predicts patient outcome and therapy response in metastatic colorectal cancer. Int J Cancer 2014; 135(11): 2633-2643.

3. Aguado M. Identificación de células tumorales circulantes en el cáncer de mama metastásico mediante Cellsearch TM System, 2006, http://www.juntadeandalucia.es/export/drup aljda/1337163261identificacion_CellSearch.pdf

4. Westwood M, vanAsselt T, Ramaekers B, et al. KRAS mutation testing of tumours in adults with metastatic colorectal cancer: a systematic review and cost-effectiveness analysis. Health Technol Assess 2014; 18: 1-132.

5. Van Cutsem E, Cervantes A, Nordlinger B, et al. Metastatic colorectal cancer: ESMO clinical practice guidelines for diagnosis, treatment and follow-up. Ann Oncol 2014; 25(Suppl. 3): iii1-9.

6. Bokemeyer C, Bondarenko I, Makhson A, et al. Fluorouracil, leucovorin, and oxaliplatin with and without cetuximab in the first-line treatment of metastatic colorectal cancer. $J$ Clin Oncol 2009; 27(5): 663-671.

7. Bokemeyer C, Bondarenko I, Hartmann JT, et al. Efficacy according to biomarker status of cetuximab plus FOLFOX-4 as first-line treatment for metastatic colorectal cancer: the OPUS study. Ann Oncol 2011; 22(7): 1535-1546.

8. Hecht JR, Mitchell E, Chidiac T, et al. A randomized phase IIIB trial of chemotherapy, bevacizumab, and panitumumab compared with chemotherapy and bevacizumab alone for metastatic colorectal cancer. J Clin Oncol 2009; 27(5): 672-680.

9. Giantonio BJ, Catalano PJ, Meropol NJ, et al. Bevacizumab in combination with oxaliplatin, fluorouracil, and leucovorin (FOLFOX4) for previously treated metastatic colorectal cancer: results from the Eastern Cooperative Oncology Group Study E3200. J Clin Oncol 2007; 25(12): 1539-1544.

10. Douillard JY, Siena S, Cassidy J, et al. Final results from PRIME: randomized phase III study of panitumumab with 
FOLFOX4 for first-line treatment of metastatic colorectal cancer. Ann Oncol 2014; 25(7): 1346-1355.

11. Peeters M, Price TJ, Cervantes A, et al. Final results from a randomized phase 3 study of FOLFIRI $\{+/-\}$ panitumumab for second-line treatment of metastatic colorectal cancer. Ann Oncol 2014; 25(1): 107-116.

12. Loupakis F, Cremolini C, Masi G, et al. Initial therapy with FOLFOXIRI and bevacizumab for metastatic colorectal cancer. N Eng J Med 2014; 371(17): 1609-1618.

13. Heinemann V, vonWeikersthal LF, Decker T, et al. FOLFIRI plus cetuximab versus FOLFIRI plus bevacizumab as firstline treatment for patients with metastatic colorectal cancer (FIRE-3): a randomised, open-label, phase 3 trial. Lancet Oncol 2014; 15(10): 1065-1075.

14. Van Cutsem E, Tabernero J, Lakomy R, et al. Addition of aflibercept to fluorouracil, leucovorin, and irinotecan improves survival in a phase III randomized trial in patients with metastatic colorectal cancer previously treated with an oxaliplatin-based regimen. J Clin Oncol 2012; 30(28): 3499-3506.

15. Kabbinavar FF, Hambleton J, Mass RD, et al. Combined analysis of efficacy: the addition of bevacizumab to fluorouracil/ leucovorin improves survival for patients with metastatic colorectal cancer. J Clin Oncol 2005; 23(16): 3706-3712.

16. Cunningham D, Lang I, Marcuello E, et al. Bevacizumab plus capecitabine versus capecitabine alone in elderly patients with previously untreated metastatic colorectal cancer (AVEX): an open-label, randomised phase 3 trial. Lancet Oncol 2013; 14(11): 1077-1085.

17. Grothey A, Van Cutsem E, Sobrero A, et al. Regorafenib monotherapy for previously treated metastatic colorectal cancer (CORRECT): an international, multicentre, randomised, placebo-controlled, phase 3 trial. Lancet 2013; 381(9863): 303-312.

18. Van Cutsem E, Peeters M, Siena S, et al. Open-label phase III trial of panitumumab plus best supportive care compared with best supportive care alone in patients with chemotherapy-refractory metastatic colorectal cancer. $J$ Clin Oncol 2007; 25(13): 1658-1664.

19. Chibaudel B, Maindrault-Goebel F, Lledo G, et al. Can chemotherapy be discontinued in unresectable metastatic colorectal cancer? The GERCOR OPTIMOX2 Study. J Clin Oncol 2009; 27(34): 5727-5733.

20. Lairson DR, Parikh RC, Cormier JN, et al. Cost-utility analysis of chemotherapy regimens in elderly patients with stage III colon cancer. Pharmacoeconomics 2014; 32(10): 1005-1013.

21. Starling N, Tilden D, White J, et al. Cost-effectiveness analysis of cetuximab/irinotecan vs active/best supportive care for the treatment of metastatic colorectal cancer patients who have failed previous chemotherapy treatment. Br J Cancer 2007; 96(2): 206-212.

22. Orchard M. A cost-effectiveness analysis of capecitabine and folfox for the adjuvant treatment of stage III colon cancer: which is the more cost-effective option in Ontario? 2009, https://tspace.library.utoronto.ca/bitstream/1807/17701/1/ Orchard_Margo_C_20096_MSc_thesis.pdf

23. Hoyle $\bar{M}$, Crathorne L, Peters J, et al. The clinical effectiveness and cost-effectiveness of cetuximab (mono- or combination chemotherapy), bevacizumab (combination with non-oxaliplatin chemotherapy) and panitumumab (monotherapy) for the treatment of metastatic colorectal cancer after first-line chemotherapy (review of technology appraisal No.150 and part review of technology appraisal No. 118): a systematic review and economic model. Health Technol Assess 2013; 17(14): 1-237.

24. Currie CJ, Poole CD, Woehl A, et al. The health-related utility and health-related quality of life of hospital-treated subjects with type 1 or type 2 diabetes with particular reference to differing severity of peripheral neuropathy. Diabetologia 2006; 49(10): 2272-2280.

25. Zeng X, Li J, Peng L, et al. Economic outcomes of maintenance gefitinib for locally advanced/metastatic nonsmall-cell lung cancer with unknown EGFR mutations: a semi-Markov model analysis. PLoS ONE 2014; 9(2): e88881.

26. Pericay C, Frías C, Abad A, et al. Análisis coste-efectividad de aflibercept en combinación con FOLFIRI en el tratamiento de pacientes con cáncer colorrectal metastásico. Farmacia Hospitalaria 2014; 38(4): 317-327.

27. Herrera AR, Piñones GL, Cázares JPC, et al. Eritrodisestesia palmoplantar por capecitabina, en una mujer con cáncer de mama. Dermatol Rev Mex 2012; 56(1): 71-73.

28. Botplusweb: Consejo General de colegios oficiales de farmacéuticos, https://botplusweb.portalfarma.com/

29. Corral J, Borràs JM, Chiarello $\mathrm{P}$, et al. Estimación del coste hospitalario del cáncer colorrectal en Cataluña. Gac Sanit 2015; 29(6): 437-444.

30. Tarifas de los servicios sanitarios prestados en los centros dependientes del Servicio Gallego de Salud y en las fundaciones públicas sanitarias. Decreto 56/2014, http://laadministracionaldia.inap.es/usuarios/noticia. asp?id $=1127470$

31. Orden $731 / 2013$ de 6 de septiembre del Consejero de Sanidad, por la que se fijan los precios públicos por la prestación de los servicios y actividades de naturaleza sanitaria de la Red de Centros de la Comunidad de Madrid, 2013, https://www.iberley.es/legislacion/orden-731-20136-septiembre-consejero-sanidad-fijan-precios-publicosprestacion-servicios-actividades-naturaleza-sanitaria-redcentros-comunidad-madrid-12162511

32. Bastida JL, Antoñanzas F, García-Altes A, et al. Propuesta de guía para la evaluación económica aplicada a las tecnologías sanitarias. Madrid: Plan Nacional para el SNS del MSC Servicio de Evaluación del Servicio Canario de la Salud; 2008 Informes de Evaluación de Tecnologías. Gac Sanit 2008; 24(2): 154-170.

33. VI Convenio colectivo marco estatal de servicios de atención a las personas dependientes y desarrollo de la promoción de la autonomía personal, Resolución de 25 de abril de 2012, de la Dirección General de Empleo, 2012.

34. Estadística INd. España en cifras, 2015, http://www.ine.es/ prodyser/espa_cifras/2015/files/assets/common/downloads/ publication.pdf

35. Briggs A, Sculpher M and Claxton K. Decision modelling for health economic evaluation (Handbooks in health economic evaluation). 1st ed. Oxford: Oxford University Press. 